\title{
Enantioselective Conjugated Addition of Vinylaluminums to Cyclic Enones
}

\section{Key words}

chiral N-heterocyclic carbenes

vinylaluminum reagents

copper

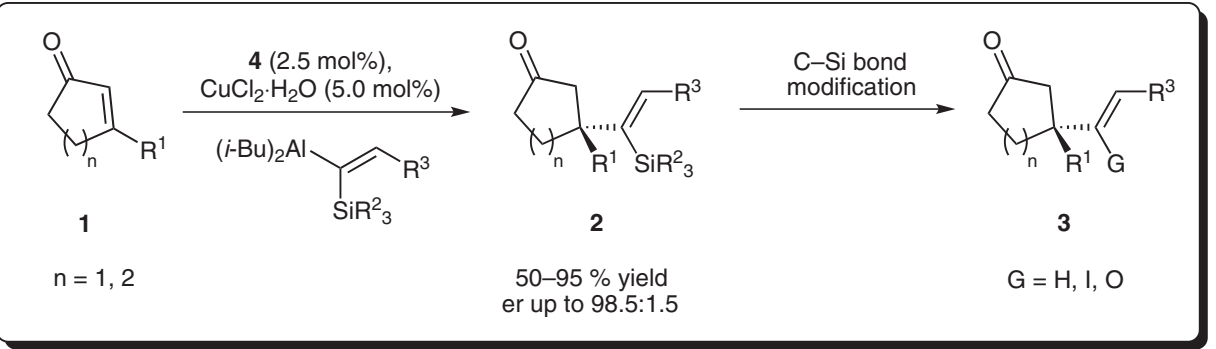

C-Si bond functionalization:

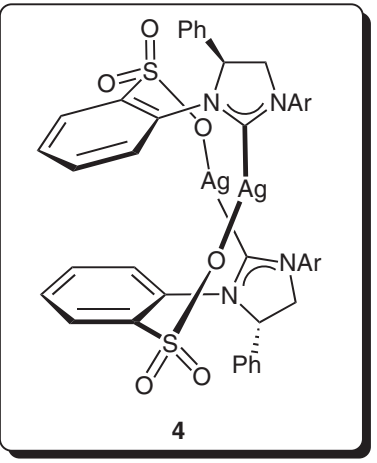

$\mathrm{Ar}=2,6-\mathrm{Et}_{3} \mathrm{C}_{6} \mathrm{H}_{3}$<smiles>CC(C)(C)C1(C)CCC(=O)C1</smiles>
5<smiles>CC1(/C(=C\O)[Y5](=O)[O-])CCCC(=O)C1</smiles>

7

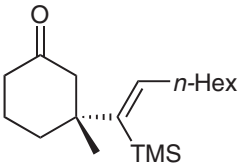

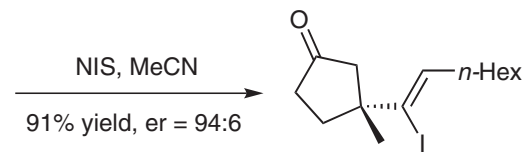

6

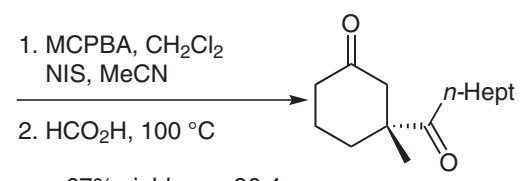

$67 \%$ yield, er $=96: 4$

8
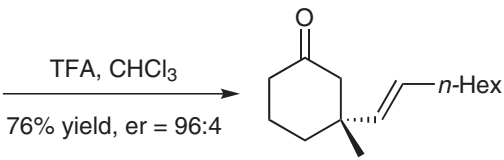

10
Significance: The development of transitionmetal-catalyzed enantioselective reactions allowing the formation of quaternary stereogenic centers is a challenging task. Herein, the authors report a highly enantioselective conjugated addition of Si-substituted vinylaluminum reagents to fiveand six-membered cyclic $\beta$-substituted enones of type 1. A chiral bidentate NHC-copper complex has been identified to facilitate the desired transformation of $\mathbf{1}$ into $\mathbf{2}$ with good to excellent yields and enantioselectivities.

SYNFACTS Contributors: Mark Lautens, Norman Nicolaus Synfacts 2011, 4, 0395-0395 Published online: 18.03.2011 Dol: 10.1055/s-0030-1259649; Reg-No.: L02111SF
Comment: The active catalyst for the enantioselective addition is easily formed in situ starting from air-stable $\mathrm{CuCl}_{2} \cdot \mathrm{H}_{2} \mathrm{O}$ and complex 4 . The reaction $(\mathbf{1} \rightarrow \mathbf{2})$ is typically finished within 15-20 minutes and the required Si-containing vinylaluminum reagents are readily available from silylacetylenes though a stereoselective hydroalumination using DIBAL-H. Furthermore, it has been shown that the enantiomerically enriched vinylsilane products can be easily protodesilylated $(\mathbf{7} \rightarrow \mathbf{8})$, oxidized $(\mathbf{9} \rightarrow \mathbf{1 0})$ or transformed into the corresponding vinyl iodides $(\mathbf{5} \rightarrow \mathbf{6})$ with good to excellent yields. 